\title{
Saúde pública e controle social: uma trajetória de avanços?
}

\author{
Jeferson Batista Silva ${ }^{1}$
}

\begin{abstract}
RESUMO
O objetivo deste artigo é discutir a efetividade dos mecanismos de controle social nas políticas públicas, com enfoque na política de saúde. Historicamente nunca tivemos no Brasil tantas instâncias e mecanismos de controle social: Conferências de políticas públicas e conselhos de políticas públicas (Assistência Social, Saúde, Infância e Adolescência, etc.). No entanto, muito se questiona sobre a efetividade destas estruturas no controle social. A relevância deste tema reside no fato de que nos discursos se propaga a importância do controle social na definição, monitoramento e avaliação das políticas públicas. Entretanto, este discurso não consegue se materializar em práticas efetivas, muitas vezes o que se observa é a coexistência de um discurso moderno com práticas tradicionais. Discutir esta temática torna-se então fundamental para a compreensão e elaboração de mecanismo para superar esta distância entre discurso e prática. Para a construção deste artigo foi utilizada a metodologia da pesquisa bibliográfica, com a leitura de autores especializados na temática. Conclui-se que a edição das leis e um discurso formal sobre o controle social não são fatores suficientes para alterar um padrão de cultura, onde ações do poder público são realizadas em nível de técnicos e ou políticos de forma bem distanciada da população geral.
\end{abstract}

Palavras-chave: Estado demiurgo, Sociedade participativa, Controle Social.

\begin{abstract}
The aim of this paper is to discuss the effectiveness of social control mechanisms in public policies, focusing on health policy. Historically we have never had so many instances and mechanisms of social control in Brazil: Public Policy Conferences and Public Policy Councils (Social Assistance, Health, Childhood and Adolescence, etc.). However, much is questioned about the effectiveness of these structures in social control. The relevance of this theme lies in the fact that the discourse propagates the importance of social control in the definition, monitoring and evaluation of public policies. However, this discourse cannot materialize into effective practices, often what is observed is the coexistence of a modern discourse with traditional practices. Discussing this theme then becomes fundamental for the understanding and elaboration of a mechanism to overcome this distance between speech and practice. For the construction of this article was used the methodology of bibliographic research, with the reading of authors specialized in the subject. It is concluded that the drafting of laws and a formal discourse on social control are not enough factors to change a culture pattern, where actions of the public power are performed at the level of technicians and or politicians very far from the general population.
\end{abstract}

Key words: Demiurge State, Participatory Society, Social Control.

\section{INTRODUÇÃO}

Desde a independência é discutido se o Brasil possui uma sociedade ativa, participativa ou se teríamos uma sociedade fragmentada e pouco participativa, Lacerda (2017) apresenta uma discussão sobre o Estado Demiurgo, a Sociedade estruturada e o modelo da complementaridade.

\footnotetext{
${ }^{1}$ Psicólogo, Cientista Político, Especialista em Terapia Comportamental, Especialista em Gestão Pública, Mestre em gestão Social e Desenvolvimento. E-mail jefersonbatis@yahoo.com.br
} 
A história brasileira é marcada pela alternância de governos centralizadores e de caráter ditatoriais (Estado Novo, Governo Ditatorial 1964-1985), Estado Demiurgo por períodos democráticos (1945-1964) e Nova República, a partir de 1985. Nesta alternância, fica evidente a visão destes governos sobre a capacidade de organização da sociedade civil brasileira.

A questão central da filosofia de gestão passa a ser empoderar a sociedade de forma que ela possa decidir sobre as principais ações em termos de atuação do Estado ou se o Estado deve ser um agente definidor de suas políticas públicas ${ }^{2}$, pois a sociedade é fragmentada e, em sua maioria, somente consegue pensar em interesses individuais e locais. Partindo desta dicotomia, o presente trabalho buscará analisar um dos instrumentos da gestão pública, implementada a partir da constituição de 1988, os conselhos de políticas públicas.

\begin{abstract}
A literatura nacional na área tem buscado avaliar a efetividade da deliberação em experiências participativas (Fuks 2007; Cunha 2010; Almeida \& Cunha 2011), a capacidade de as instituições participativas influenciarem, controlarem ou decidirem o conteúdo das políticas públicas (Côrtes 2002; Avritzer 2011; Vaz \& Pires 2011; Vaz 2011), a relação entre participação e representação (Gurza Lavalle, Houtzager \& Castello 2006; Avritzer 2007; Lüchmann 2007) e o potencial das práticas participativas e deliberativas no fortalecimento das instituições representativas como o Congresso nacional (Pogrebinschi \& Santos 2011) ( SANTOS ; GUGLIANO 2017, p 4 ).
\end{abstract}

Nossa discussão perpassará pela avaliação do impacto dos mecanismos de controle da política pública de saúde, especificamente os conselhos de saúde. O intuito será o de avaliar a efetividade ou não destes novos instrumentos e espaço de participação, além da definição das ações desta política pública.

Esta questão norteou o objetivo central do presente artigo, que buscou, na pesquisa bibliográfica, por meio de levantamento em livros e artigos científicos respostas para tal questionamento.

Este artigo inicia-se com uma breve introdução, onde o tema de pesquisa é apresentado, bem como sua importância, o problema a ser estudado e o propósito. Posteriormente, destaca breve apresentação sobre Estado Demiurgo e Sociedade participativa. Em seguida, explana sobre a história da saúde pública no Brasil, realiza a discussão sobre a efetividade dos conselhos de saúde na definição das ações desta política pública, e, por fim, estão colocadas as conclusões.

\footnotetext{
2 "Políticas públicas" são diretrizes, princípios norteadores de ação do poder público; regras e procedimentos para as relações entre poder público e sociedade, mediações entre atores da sociedade e do Estado. São, nesse caso, políticas explicitadas, sistematizadas ou formuladas em documentos (leis, programas, linhas de financiamentos) que orientam ações que normalmente envolvem aplicações de recursos públicos (TEIXEIRA, 2002, p.2).
} 


\section{ESTADO DEMIURGO OU SOCIEDADE PARTICIPATIVA?}

Por Estado Demiurgo entende-se um Estado forte que busca conduzir as ações da sociedade, pois considera que esta mesma sociedade é fraca e fragmentada.

No modelo demirugico, o Estado tem a função de estruturar a sociedade, criar condições sociopolíticas para que esta se desenvolva liberal ou que atuar como principal ator social nas modernas democracias industriais de massa. O protagonismo estatal é justificado pela visão de que a sociedade é desarticulada e incapaz de representar seus próprios interesses, ou é dominada por interesses mesquinhos e particularísticos, de modo que a noção de bem comum só pode ser estabelecida com a ação do Estado (LACERDA, 2017, p. 108).

Como modelo de sociedade estruturada podemos pensar em grupos sociais organizados e com capacidade de reivindicar e apontar possibilidades de melhorias das ações do poder público.

A sociedade organizada é organizada e articulada: Os grupos são estruturados e têm interesses definidos ansiando influenciar as políticas públicas e promovendo, discussões e trocas de idéias. Esses grupos podem ser os mais variados possíveis: Associações econômicas (de agricultores, de industriais, de comerciantes, de banqueiros, de trabalhadores, etc.). Associações culturais, partidos políticos, igrejas, etc.(...) (LACERDA, 2017, p. 108).

O modelo da complementaridade representaria um meio termo entre o Estado Demiurgo e a Sociedade estruturada, onde o Estado conduziria uma sociedade pré-organizada até o momento em que esta se emancipar e se organizar, conduzindo a partir deste ponto, a vida social com pouca ou nenhuma interferência do poder público.

O modelo de complementariedade - família teórica do Estado e da sociedade como polos ativos - conjuga o otimismo e o pessimismo em relação ao Estado e a sociedade com a expectativa otimista sobre o futuro dessas instituições. Em outras palavras, para essa família teórica, tanto o Estado quanto a sociedade apresentam problemas e defeitos que devem ser corrigidos a fim de se estabelecer uma relação mais adequada, eventualmente mais harmoniosa no futuro (LACERDA, 2017, p. 108).

Esta discussão perpassou toda a história monárquica e republicana nacional até os dias de hoje, com maior ou menor presença do Estado na vida do país.

Vários são os estudiosos que escreveram e discutiram a atuação do Estado e a sua própria organização administrativa. José de Alencar, Alberto Torres, Oliveira Viana e Francisco Campos seriam representantes do Estado Demiurgo. Bariani (2007, p.163) ao falar sobre o pensamento de Alberto Torres diz: 
Incomodava particularmente o autor a inorganicidade da sociedade brasileira, a qual teria sido propiciada pela sua conformação de improviso, pela transplantação de instituições e por excessos do liberalismo, situação essa que se expressaria na fragilidade do Estado, na ausência de sociedade e povo, de solidariedade, de estruturação socioeconômica e sentimento coletivo e patriótico, que viabilizariam a existência plena da Nação. Para ele, nos "países de origem colonial”, nos quais se deveria impor artificialmente a nacionalidade, seria mister a formação "por convicção racional" de tal sentimento, a criação "pelo alto" da consciência nacional - matériaprima da organização da Nação.

Autores como: Tavares Bastos, Joaquim Nabuco, Rui Barbosa e Raimundo Faoro seriam representantes das ideias de uma sociedade nacional ativa e participativa. E como representantes da linha de pensamento da complementariedade entre Estado e sociedade, podemos citar: Teixeira Mendes, Caio Prado Junior, Sérgio Buarque de Holanda e Bresser Pereira.

No Brasil, decorrente de sua formação histórica, sempre se vivenciou períodos de governos populistas que buscavam trabalhar ou criar a imagem que se trabalhava a autonomia da população e períodos de governos de caráter centralizador e não democráticos. Foi assim durante o período populista de Getúlio Vargas (1930-1937) e na sequência o período ditatorial do Estado Novo (1937-1945). Após o fim da segunda guerra mundial, seguindo um efeito mundial, o Brasil vivencia um período democrático populista (1946-1964) para novamente inserir-se em novo período de um regime ditatorial, o regime militar (1964-1985).

Desta forma, para entendermos nosso atual período democrático (1985 até os dias atuais) precisaremos direcionar nossa análise para o período histórico anterior, ou seja, o período da ditadura militar brasileira. A compreensão do modelo de Estado deste período, bem como da organização de suas políticas públicas, com ênfase sobre a política de saúde, será nosso foco de análise.

\section{GOLPE DE 64 E A POLÍTICA DE SAÚDE NO BRASIL}

No ano de 1964 o Brasil vivenciou um golpe civil-militar que destituiu o Presidente João Goulart, o qual conduziu o país à uma ditadura militar. Neste período, observou-se uma grande centralização do poder junto ao governo central, Federal, em detrimento das unidades federadas, estados e municípios. Governadores e prefeitos não eram mais eleitos e sim indicados pelo presidente da república. Tratava-se de uma clara forma de controle, considerando todo o rompimento institucional do período. Santos (1979), Fleury (2006) apud 
Gurgel, Justen (2013) explicam que o Estado Brasileiro, a partir de 1964, fortalece o caráter centralizador e planejador. A política desenvolvimentista é o foco, observam-se investimentos em vários segmentos, incluindo as políticas sociais (Saúde, Habitação, Desenvolvimento social), mas, na realidade, tratava-se de uma estratégia dentro do contexto da "cidadania em recesso", que seria a ausência de participação dos beneficiários, ausência de controle público/social e a administração de caráter burocrático sem diálogo com os interessados. Notase aqui, a clara manifestação do estado demiurgo, conforme já explicado anteriormente. Burocratas, distantes da realidade, planejavam as políticas públicas e ações do Estado, considerando que sabiam o que seria melhor para a população a ser beneficiada.

Dentre as ações centralizadoras do governo ditatorial destaca-se a unificação dos IAPs - Institutos de Aposentadoria e Pensões, criando o INPS - Instituto Nacional de Previdência Social. Observa-se, de forma nítida, o objetivo de centralização e controle sobre o instituto. Estes estavam divididos em categorias profissionais, os IAPs, que tinham uma gestão tripartite, a partir da unificação dos institutos o governo federal e o único controlador do novo instituto.

Até 1964, a assistência médica previdenciária era prestada, principalmente pela rede de serviços próprios dos IAPs, composta por hospitais, ambulatórios e consultórios médicos. A partir da criação do INPS, alegando a incapacidade da rede própria de serviços fornecer assistência médica a todos os beneficiários, foi priorizada a contratação de serviços de terceiros no modelo adotado pelo Instituto de Aposentadoria e Pensões dos Industriários IAPI (GIOVANELLA et al, 2012, p.325).

Outro ponto que é marcante é a busca da contratação de serviços terceirizados de saúde.

No caso da previdência, o INPS passou a ser o grande comprador de serviços privados de saúde e, dessa forma estimulou um padrão de organização da prática médica orientado pelo lucro. A contratação de serviços privados de saúde, especialmente hospitais e laboratórios era feita por meio de credenciamento e remunerada por Unidades de Serviço (...). Na medida em que os preços tabelados em US eram Baixos e na ânsia de tornar a medicina uma atividade lucrativa, os serviços inventavam pacientes ou ações que não tinham sido praticadas ou ainda escolhiam fazer apenas aquelas que eram mais bem remuneradas, como o parto cesariana em vez do parto normal (GIOVANELLA et al, 2012, p.325).

Com o grande volume de pessoas entrando no mercado de trabalho e uma população em sua maioria de jovens, observa-se que, com a centralização do sistema dos IAPs, o governo federal passa a controlar, exclusivamente, um grande volume de capitais, com os quais ele passa a financiar o setor privado de saúde.

Criaram-se, assim, convênios e contratos com a maioria dos médicos e hospitais existentes no país. Essa forma de organização levou à criação em 1978 do Instituto Nacional de Assistência Médica da Previdência Social (INAMPS), que pagava aos hospitais particulares o atendimento dos segurados. Além disso, levou-se, também, à 
criação de um sistema médico-industrial, com aumento do consumo de medicamentos, baseados em uma medicina curativista; capitalização dos grupos envolvidos nesse sistema e, ainda, ampliação de hospitais da rede privada (BADARÓ; SANTOS , 2015, p.59).

Trata-se de um período de grande crescimento dos grupos de prestadores privados de serviços de saúde que serão pagos em unidades de serviços. Tal forma de pagamento propiciará significativo grau de corrupção e de desvios de dinheiro através de guias de pagamentos de serviços superfaturados. Atentos à todo este estado de coisas, observa-se o surgimento de um movimento de questionamento. Este movimento era encabeçado por trabalhadores dos serviços públicos e por grupos de professores e alunos que fundaram os departamentos de medicina preventiva nas universidades públicas a partir da reforma universitária de 1968. Este movimento será conhecido como Movimento de Reforma Sanitária Brasileira.

Chamamos de movimento sanitário, o movimento de profissionais de saúde e de pessoas vinculadas ao setor que compartilha o referencial médico-social na abordagem dos problemas de saúde e que por meio de determinadas práticas políticas e teóricas, busca a transformação do setor saúde no Brasil, em prol da melhoria das condições de saúde e de atenção à saúde da população brasileira, na consecução do direito de cidadania (GIOVANELLA et al, 2012, p.341).

O Movimento de Reforma Sanitária Brasileira se unirá a outros movimentos de base na busca do retorno do Brasil à democracia e buscará que esta democracia se faça presente também na saúde. Marca significativa deste movimento de luta pelo retorno às bases democráticas e da participação da sociedade na definição das ações e na estruturação da política nacional de saúde será a $8^{\text {a }}$ Conferência Nacional de Saúde. Esta conferência é um dos marcos de constituição do SUS e nela que serão estabelecidas as principais referências que balizarão os debates da constituinte e marcarão os princípios constitucionais de saúde previstos em nossa carta magna,

Com ampla participação das organizações da sociedade civil de todo o país como delegados eleitos, incluindo as representações sindicais, das associações de profissionais de saúde, de movimentos populares em saúde, do Cebes, da Abrasco, a conferência discutiu temas que se desdobraram em diretrizes válidas ainda hoje: 1) busca da equidade, 2) Garantia de acesso universal às ações e serviços de saúde, 3) Aumento do financiamento público no setor saúde, 4) unificação e integração das ações do ponto de vista de seu conteúdo: preventivas, curativas e de reabilitação e do ponto de vista de sua gestão, integração entre os níveis federal, estadual e municipal de governo e unicidade das estruturas gestoras em cada nível e 5) Atribuição de maiores poderes à população para participar ativamente na formulação, implementação e controle das ações de saúde (GIOVANELLA et al, 2012, p.341)

O ano de 1985 marca o fim do período ditatorial e o início da Nova República brasileira. O dia $1^{\circ}$ de Fevereiro de 1987 baliza o início dos trabalhos da Assembléia Nacional Constituinte de 1988, ano em que é promulgada a nova constituição brasileira. De caráter Social Democrático, esta constituição ficou conhecida como a "Constituição Cidadã", pois buscava a 
retomada da plena democracia em nosso país através das conquistas sociais e especialmente da participação social popular na definição das ações do poder público, sinal da retomada da crença sobre a sociedade estruturada. Um ponto que marca profundamente esse novo tempo da república será a constitucionalização de um serviço de saúde público universal a toda a população brasileira, trata-se dos fundamentos de constituição do SUS. Nossa Constituição Federal em seus artigos, artigos 196 a 200, no capítulo II do título VIII, seção da Saúde, deixa claro que o sistema de Saúde Brasileiro será constituído em um tripé onde se evidenciam os princípios de Universidade, Equidade e Integralidade.

A saúde tem como fatores determinantes e condicionantes, entre outros, a alimentação, a moradia, o saneamento básico, o meio ambiente, o trabalho, a renda, a educação, o transporte, o lazer e o acesso aos bens e serviços essenciais; os níveis de saúde da população expressam a organização social e econômica do País (BRASIL, 1990, p.1).

O estabelecimento de um sistema universal de saúde estruturado nos três níveis de governo: Municipal, Estadual e Federal representa por si só, um avanço extraordinário para um país de tamanho continental e tantas desigualdades. Mas devemos ressaltar que outra marca se faz presente no processo de constituição do SUS, o controle social, a participação popular na definição de suas ações.

No caso das experiências participativas no Brasil, a implementação dos Conselhos Gestores de Políticas Públicas é um exemplo neste sentido. (...) a trajetória das lutas e reivindicações da sociedade civil nos anos 70 e 80 fez imprimir, na Constituição de 1988, um conjunto de instrumentos participativos que, a exemplo dos Conselhos Gestores nas áreas da saúde, assistência social e criança e adolescente, pretendem reordenar os processos decisórios através da ampliação do público e da reformulação na natureza da decisão, pautada pelo debate público e coletivo e pela universalização dos direitos sociais (LUCHMANN, 2002, p.33).

Considera-se como lei criadora do SUS, a Lei 8.080/90, a qual regulamenta o Sistema Único de Saúde. Esta lei foi promulgada durante o governo do Presidente Collor, primeiro presidente eleito democraticamente após 21 anos de Ditadura. Período este, onde a população foi afastada de todos os processos de participação da vida política e social do país. Destaca-se que nesta lei já esta prevista, de forma clara, a participação e controle social da população sobre o novo sistema de saúde.

I - universalidade de acesso aos serviços de saúde em todos os níveis de assistência; II - integralidade de assistência, entendida como um conjunto articulado e contínuo das ações e serviços preventivos e curativos, individuais e coletivos, exigidos para cada caso em todos os níveis de complexidade do sistema; III - preservação da autonomia das pessoas na defesa de sua integridade física e moral; IV - igualdade da assistência à saúde, sem preconceitos ou privilégios de qualquer espécie; $\mathrm{V}$ - direito à informação, às pessoas assistidas, sobre sua saúde; VI - divulgação de informações quanto ao potencial dos serviços de saúde e sua utilização pelo usuário; VII - 
utilização da epidemiologia para o estabelecimento de prioridades, a alocação de recursos e a orientação programática; VIII - participação da comunidade; IX descentralização político-administrativa, com direção única em cada esfera de governo: a) ênfase na descentralização dos serviços para os municípios; b) regionalização e hierarquização da rede de serviços de saúde; X - integração, em nível executivo, das ações de saúde, meio ambiente e saneamento básico; XI - conjugação dos recursos financeiros, tecnológicos, materiais e humanos da União, dos Estados, do Distrito Federal e dos Municípios, na prestação de serviços de assistência à saúde da população; XII - capacidade de resolução dos serviços em todos os níveis de assistência; XIII - organização dos serviços públicos de modo a evitar duplicidade de meios para fins idênticos (BRASIL,1990, p.1. Grifo do autor).

Com objetivo de fortalecer o processo de constituição do SUS, outra lei federal foi promulgada, Lei 8.142/90. Esta abordará um ponto chave para qualquer sistema de política pública, o financiamento e também a participação social. Presente em duas leis federais, oportuno destacar a importância que foi dada por nosso congresso nacional à participação social e controle público sobre a política pública de saúde. É através da lei 8.142/90 que se constituem os conselhos de saúde.

O Conselho de Saúde, em caráter permanente e deliberativo, órgão colegiado composto por representantes do governo, prestadores de serviço, profissionais de saúde e usuários, atua na formulação de estratégias e no controle da execução da política de saúde na instância correspondente, inclusive nos aspectos econômicos e financeiros, cujas decisões serão homologadas pelo chefe do poder legalmente constituído em cada esfera do governo (BRASIL, 1990, p.1).

Observa-se que nossa constituição e um conjunto de leis buscaram a retomada da participação popular com relação à definição das ações do poder público. No entanto, questiona-se a efetividade deste conjunto de leis na mudança cultural, tanto da população quanto dos agentes do poder público. Nossas discussões perpassaram este ponto buscando trazer mais um olhar sobre estes processos.

\section{CONTROLE SOCIAL E CULTURA DE PARTICIPAÇÃO}

A discussão sobre o controle social esta intrinsecamente ligada à questão da cidadania $^{3}$ e seu exercício. Este exercício, a participação cidadã ${ }^{4}$, mostra às pessoas que elas

\footnotetext{
${ }^{3}$ A origem da palavra cidadania vem do latim civitas, que quer dizer cidade. Na Grécia antiga, considerava-se cidadão aquele nascido em terras gregas. Em Roma a palavra cidadania era usada para indicar a situação política de uma pessoa $\mathrm{e}$ os direitos que essa pessoa tinha ou podia exercer. Juridicamente, cidadão é o indivíduo no gozo dos direitos civis e políticos de um Estado. Em um conceito mais amplo, cidadania quer dizer a qualidade de ser cidadão, e consequentemente sujeito de direitos e deveres (Secretária da Justiça, Trabalho e Direitos Humanos, 2019).

${ }^{4}$ Participação cidadã é o processo complexo e contraditório entre sociedade civil, Estado e mercado, em que os papeis se redefinem pelo fortalecimento dessa sociedade civil mediante a atuação organizada dos indivíduos,
} 
são capazes de interferir nos destinos das administrações públicas de forma a contribuir para o desenvolvimento de sua cidade, de seu bairro. Esta capacidade, este empoderamento, emancipa as pessoas e muda sua postura de agentes passivos postulantes a benefícios "dados" pelas gestões públicas para cidadãos reivindicativos e colaboradores para o benefício comum da localidade. Robert Putnam (2006) chama esta capacidade de capital social e identifica que estruturas sociais (instituições) que facilitam o contato e a troca entre cidadãos favorecem sua capacidade de debate sobre as questões da cidadania, bem como a capacidade de intervir sobre estas. Desta forma podemos afirmar que controle social em políticas públicas perpassa a discussão sobre organização social de uma dada sociedade. Podemos apresentar esta discussão sobre dois olhares: O olhar institucional e o olhar dos agentes, dos cidadãos. Com relação ao olhar institucional:

Putnam destaca o duplo papel das instituições: i) as instituições moldam a política, influenciando os resultados porque moldam a identidade, o poder e a estratégia dos atores; e ii) as instituições são moldadas pela história, em que os indivíduos podem "escolher" suas instituições, mas não o fazem em circunstâncias que eles mesmos criaram, e suas escolhas, por sua vez, influenciam as regras dentro das quais seus sucessores fazem suas escolhas (PUTNAM, 2007 apud CAVALCANTI, 2017, p.92 )

A capacidade de se posicionar e apresentar suas ideias sobre um determinado assunto.

É a prevalência desses traços tradicionais que motiva O'Donnell (1988) a considerar a democracia da América Latina como um tipo particular de democracia e a adjetivála como "delegativa", isto é, situação na qual ocorrem eleições livres, mas o vencedor do processo eleitoral está autorizado a governar da maneira que lhe parecer conveniente, não necessitando atuar em conformidade com o prometido durante a campanha eleitoral. Em outras palavras, sacrificando a accountability (PINHO; SACRAMENTO, 2009, p.1361).

Conforme se busca construir neste texto, desde a independência deste país se discute a existência de uma sociedade civil organizada ou não.

Observa-se nitidamente na história brasileira uma alternância de governos populistas e ditatoriais. Estas formas de governo representavam a compreensão de grupos de poder sobre a sociedade brasileira e a partir deste ponto observou-se o afastamento ou controle sutil sobre a população de forma a não permitir sua implicação, envolvimento e aprendizado sobre a participação e controle do poder público.

grupos ou associações. Este fortalecimento dá-se, por um lado, com a criação e exercício de direitos. Implica também o controle social do Estado e do mercado, segundo parâmetros definidos e negociados nos espaços públicos pelos diversos atores sociais e políticos (TEIXEIRA, 2002, p.30). 
Ser cidadão num regime democrático significa possuir uma série de direitos, entre os quais a prerrogativa de participar da escolha de seus governantes e de influir nas suas decisões. Mas significa, também, uma série de obrigações sociais, entre as quais a de participar daquelas atividades diretamente vinculadas à seleção dos governantes e da vigilância sobre as suas ações (ROCHA, 2011, p. 84 e 85).

Silva (2018) citando Patemam (1992) Sabioni, Ferreira, Braga, Almeida (2016) afirma que estes autores apresentam o processo de participação como um processo educacional onde a prática participativa qualifica esta participação, ou seja, quanto mais se participa, melhor fica a participação.

Partindo deste pressuposto podemos imaginar que os constantes processos de rupturas democráticas característicos de nossa república são fatores de forte impacto no processo de aprendizagem da democracia e da participação. Isto não só em relação à população, mas também com relação aos agentes, servidores públicos efetivos ou eletivos. Destaca-se a estrutura cultural dos agentes públicos, culturalmente nosso Estado esteve impregnado do que podemos chamar de patrimonialismo. Uma cultura de uso do Estado em benefício próprio. Podemos perceber que este padrão ainda é muito forte na atuação do Estado brasileiro, seja em nível municipal, estadual ou federal. Desta forma, promover a participação da população em relação ao controle social seria um contracenso aos interesses de grupos de poder. Podemos afirmar que em boa parcela das ações do poder público estes mecanismos de controle social, os conselhos de políticas públicas, são colocados à parte nas decisões das políticas públicas.

Silva (2018) citando Filgueiras (2010) e Pinheiro (2016) ressalta que o "poder público" pode ter interesse no segredo, pois um conjunto de múltiplos interesses individuais de cada funcionário como: cargos, promoções, favores, poderia favorecer a omissão de informações relevantes ao controle social. $\mathrm{O}$ interesse individual colocado à frente do interesse coletivo.

\begin{abstract}
(...) a instauração dos Conselhos de Saúde como forma de representação no controle social é efeito das movimentações por parte dos profissionais da saúde e da sociedade civil. No entanto, em diversos municípios, essa implantação é resultado dos incentivos do Ministério da Saúde, com repasses de recursos federais. Segundo estes autores, os recursos devem ser controlados por CMSs. Como resultado, o processo criou Conselhos com diferentes seguimentos, como, por exemplo, aqueles que estão efetivamente fiscalizando os gestores do SUS e os que foram instaurados como mera formalidade. Tal cenário evidencia a disparidade dos municípios em relação à população, à oferta de serviços de saúde e ao potencial de investimento na saúde. ( PATSY; TROIAN, GOULARTE, 2016, p. 61).
\end{abstract}

Silva (2018) citando Gohn (2011) e Serafim (2008) aponta que os maiores obstáculos ao pleno exercício do controle social seriam a impossibilidade de acesso às informações realmente relevantes, o atravessamento político partidário nos espaços institucionalizados de 
controle social, como conselhos de políticas públicas, a linguagem inadequada (muito técnica) dos documentos e dos debates e, por fim, o descomprometimento do poder público com a participação, de forma objetiva, com relação ao controle social.

Não é necessário aprofundar muito nas leituras e estudos para que seja possível enumerar algumas dezenas de casos que corroboram esta afirmativa. Sendo assim, considerase fundamental o aprofundamento da democracia com a ampliação dos mecanismos de participação popular.

\section{CONSIDERAÇÕES FINAIS}

Na construção deste artigo percorremos o processo histórico de constituição do Estado brasileiro, bem como visões de como deveria ser a perspectiva de constituição deste Estado: um Estado potente e centralizador, organizador da vida nacional ou um Estado descentralizador, considerando que a sociedade poderia se organizar de forma a permitir a instituição de uma sociedade estruturada. Observou-se que ao longo da história nacional, o Brasil oscilou entre governos ora com a primeira visão ora com a segunda visão.

Esta estruturação do poder público de modo pendular, com impacto marcante dos períodos ditatoriais, será crucial na quebra da formação de uma cultura participativa mais incisiva e amadurecida. O período da ditadura militar (1964-1985) será muito marcante na dificuldade, ou melhor, dizendo, na limitação da constituição de uma cultura de participação. Patemam (1992) fala do processo de participação como um processo educacional onde a prática participativa qualifica esta participação, ou seja, quanto mais se participa, melhor fica a participação. Participação é um comportamento aprendido e deve ser sempre exercido e estimulado de forma que possa ser aperfeiçoado e transmitido.

O período ditatorial prejudicou ambos. Outro ponto, que também é fundamental avaliarmos, relaciona-se à constituição de culturas e a posição dos trabalhadores em políticas públicas.

Cultura significa todo aquele complexo que inclui o conhecimento, a arte, as crenças, a lei, a moral, os costumes e todos os hábitos e aptidões adquiridos pelo ser humano não somente em família, como também por fazer parte de uma sociedade da qual é membro. (MELO, 1995, p.10). Grifos do autor

Na citação acima, o objetivo é destacar "os costumes, os hábitos adquiridos pelo ser humano por fazer parte de uma sociedade", eu acrescentaria, de um grupo ou de grupos 
específicos. Desta forma, buscamos discutir que o processo de aprendizado se constitui em cultura, práticas diárias, tanto de cidadãos quanto de operadores das políticas públicas.

O legado cultural de uma sociedade pode inseri-la em duas dinâmicas distintas, num círculo virtuoso, em que confiança e cooperação se auto reforçam, ou num círculo vicioso, em que a desconfiança entre os agentes e destes em relação às instituições gera um cenário no qual é racional não cooperar ( CAVALCANTE, 2017, p.93)

Este conceito é fundamental e estruturante para abrirmos uma discussão sobre como nosso comportamento aprendido necessita de tempo para mudar e como é necessário mudanças no meio para que estas mudanças de comportamento sejam realmente efetivas. Há um sistema de retroalimentação que sustenta a baixa participação social nas estruturas de controle social, bem como a cultura dos operadores das políticas públicas na manutenção da baixa participação social nos mecanismos de controle. Silva (2018, p.57) apresenta a seguinte compreensão:

A experiência indica que é possível ter vários mecanismos para se criar uma figura de
participação, mas mantendo o controle exercido pelos mesmos grupos tradicionais.
Esta constatação é consubstanciada pela observação da dificuldade que o público ou
os representantes indicados por eles têm de avaliar os documentos e prestações de
contas apresentados pelo poder público, bem como compreender as informações que
ali são apresentadas. Observa-se também que o discurso proposto pelos técnicos acaba
por ser hermenêutico, impedindo ou desfavorecendo a discussão com os
representantes populares.

Podemos perceber que foi uma grande preocupação das lideranças sociais brasileiras e posteriormente dos deputados constituintes grafar em nossa constituição e nas leis posteriores dela derivadas, a importância do envolvimento da população nos mecanismos de controle social.

Cavalcante (2017) discute a concepção de que as instituições podem ser divididas em duas dimensões, que são as leis impostas pelo Estado e as informais que compreende o conjunto de regras estabelecidas pelos indivíduos e que emerge de sua interação em sociedade. A criação dos espaços institucionais é de extrema relevância para o desenvolvimento da cidadania e para o desenvolvimento, ou mesmo anteriormente para a criação, dos mecanismos de controle social.

No entanto, pelos longos anos de afastamento da possibilidade de participação e da própria ausência de cobranças e controle sobre os agentes públicos, observa-se que os mecanismos legais não são por si só, mecanismos criadores desta cultura de participação. Torna-se tão relevante ou até mais, criar "escolas da participação" criar mecanismos de contato e troca entre as lideranças sociais e a população de forma a instigá-los e estimular a participação, bem como a capacitação para a participação. O simples estar presente e dizer sim nas reuniões 
ordinárias ou extraordinárias dos conselhos de políticas públicas para as propostas dos agentes representantes do poder público não significa participação. É preciso capacitações para se compreender planilhas, leis prestações de conta, algo que a maioria absoluta dos conselheiros de políticas públicas, incluídos aqui os conselheiros dos vários conselhos municipais e estaduais de saúde por todo o Brasil, em sua maioria, não possuem.

\begin{abstract}
(...) fortalecer a capacidade das instituições e organizações locais por meio de programas de formação de líderes; criar condições apropriadas para a articulação entre atores em níveis local e regional; apoiar os atores sociais coletivos no nível local, através de recursos técnicos e tecnológicos a fim de que possam interagir no meio garantindo a sustentabilidade; e incentivar alianças locais sob um leque de oportunidades de iniciativas de desenvolvimento em que os recursos sejam disponibilizados e orientados para o melhoramento dos serviços básicos, infraestrutura, geração de novas alternativas de produção e renda, e educação voltada para o desenvolvimento da cidadania (TENÓRIO; DUTRA; MAGALHÃES, 2004, p.4).
\end{abstract}

A participação e o controle social são sementes que demoram muito a germinar, precisam de muito cuidado e tempo, algo que em nossa história se mostra sempre inconcluso e interrompido. Esperamos que neste novo período democrático, nossa semente da participação do controle social e da cidadania tenha tempo e nutrientes suficientes para o seu pleno desenvolvimento.

\title{
REFERÊNCIAS
}

BADARÓ, Rodrigo de Carvalho; SANTOS, Thaís dos. O direito à saúde no Brasil: uma análise dos impactos do golpe militar no debate sobre universalização da saúde. Direito Constitucional - Revista do Programa de Pós-Graduação em Direito da UFBA. v.25, n27 (2015). Acesso em 15/09/2019.

BARIANI, Edison. O ESTADO DEMIURGO: Alberto Torres e a construção nacional. CADERNO CRH, Salvador, v. 20, n. 49, p. 161-167, Jan./Abr. 2007. Acesso em 15/09/2019

BRASIL. Presidência da República. Lei 8.080 de 19 de setembro de 1990. Disponível em: <http://www.planalto.gov.br/ccivil_03/leis/18080.htm>. Acesso em: 15 de Setembro de 2019.

. Presidência da República. Lei 8.142 de 19 de setembro de 1990. Disponível em: <http://www.planalto.gov.br/ccivil_03/leis/18142.htm>. Acesso em: 15 de Setembro de 2019.

CARVALHO, Patsy; TROIAN, Alessandra; GOULARTE, Jeferson Luis Lopes. A efetividade do conselho municipal de saúde de Santana do Livramento, Rio Grande do Sul: uma análise a partir das leis n. $^{\circ} 8.080 / 1990$ e 8.142/1990. SOCIAIS E HUMANAS, SANTA MARIA, v. 29, n. 02, mai/ago 2016, p. $58-77$. https://periodicos.ufsm.br/sociaisehumanas/article/view/22353. Acesso em: 13/10/2019. 
CAVALCANTE, Carolina Miranda. Papel do capital social e das instituições no desenvolvimento econômico. Revista Desenvolvimento Socioeconômico em debate. RDSD v.3 n.1 (2017). 85-101 http://periodicos.unesc.net/RDSD/article/view/3558. Acesso em $13 / 10 / 2019$.

GIOVANELlLA, Ligia, et al. Política e sistema de saúde no Brasil. $2^{\text {a }}$ edição revista e ampliada. Rio de Janeiro: Editora Fiocruz, 2012.

Governo do Paraná. Secretaria da Justiça Trabalho e Direitos Humanos. 2019. O que é

Cidadania? 〈http://www.dedihc.pr.gov.br/modules/conteudo/conteudo.php?conteudo=131> acesso em 28/10/2019.

GURGEL, Cláudio; Agatha JUSTEN. Controle social e políticas públicas: a experiência dos Conselhos Gestores. Rev. Adm. Pública — Rio de Janeiro 47(2):357-378, mar./abr. 2013. Acesso em 15/09/2019.

LACERDA, Gustavo Biscaia. Pensamento Social e Político Brasileiro. Curitiba: InterSaberes, 2017.

MELO, Luis Gonzaga. Antropologia Cultural: iniciação, teoria, temas. Petrópolis: Vozes, 1995.

PATEMAM, Carole. Participação e teoria democrática. Trad. Luiz Paulo Rouanet. São Paulo: Paz e terra. 1992.

PUTNAM, Robert. Comunidade e democracia: A experiência da Itália moderna. 5 ed., São Paulo: FGV Editora, 2006.

SANTOS, Priscilla R.; GUGLIANO, Alfredo A. Efetividade das políticas participativas no governo brasileiro: o Conselho de Desenvolvimento Econômico e Social. Rev. Sociol. Polit., v. 23, n. 56, p. 3-19, 2015. http://www.scielo.br/scielo.php?script=sci_arttext\&pid=S010444782015000400003. Acesso em 29/10/2019.

SILVA. Jeferson Batista Silva. Accountability e Gestão Pública: possibilidades e limites da participação no aperfeiçoamento das políticas públicas. Revista Desenvolvimento Econômico em Debate. RDSD v.4 n.1 (2018) 41-59. http://periodicos.unesc.net/RDSD/article/view/4269/4176. Acesso em 28/10/2019.

TEIXEIRA, Elenaldo. O local e o global: Limites e desafios da participação cidadã. $3^{\mathrm{a}}$ ed., São Paulo: Cortez, 2002.

TENÓRIO, Fernando Guilherme; DUTRA, José Luís de Abreu; MAGALHÃES, Carla Marisa Rebelo de. Gestão social e desenvolvimento local: uma perspectiva a partir da cidadania deliberativa. In: ENCONTRO ANUAL DA ASSOCIAÇÃO NACIONAL DOS PROGRAMAS DE PÓSGRADUAÇÃO EM ADMINISTRAÇÃ̃O, 28. 2004, Curitiba. Anais... [Rio de Janeiro]: ANPAD, 2004. 1 CD-ROM. Área e número: GSA-2042. 